\title{
Pengaruh Kapasitor Shunt Terhadap Susut Transmisi Sistem Interkoneksi Sulselbar Berbasis DIgSILENT Power Factory 15.1.
}

\author{
Marwan $^{1}$, Nurhayati ${ }^{1}$, Andi Sultan A. Al Qahfi ${ }^{1, a}$ dan Rizqi A. Burhan ${ }^{1, b}$ \\ ${ }^{1}$ Jurusan Teknik Elektro, Program Studi Teknik Listrik, Politeknik Negeri Ujung Pandang, \\ Jl. Perintis Kemerdekaan km. 10 Makassar 90245 \\ asultanalauddin05@gmail.com, \\ burhanrizqiamalia@yahoo.com
}

\begin{abstract}
The aim of this research is to investigate the influence of shunt capacitor on losses of interconnection system of Sulselrabar transmission lines. In this study, DIgSILENT Power Factory 15.1 software is used to simulate the power flow in the system under study. There are three conditions applied in this study; real condition, in condition of all capacitors activated and in condition of all capacitors inactivated. Obtained results show that there are differences in the value of the losses among these three conditions, where the lowest losses is occurred at the second condition with 1,69\% and the highest losses occurred at the third condition with $1,76 \%$.
\end{abstract}

Keywords: Capacitor, shunt, simulation, transmission losses, DIgSILENT

\footnotetext{
Abstrak - Tujuan dari penelitian ini adalah untuk melihat pengaruh kapasitor shunt terhadap susut transmisi sistem interkoneksi Sulselrabar. Metode yang digunakan adalah dengan melakukan simulasi aliran daya menggunakan software DIgSILENT Power Factory 15.1. Pada penelitian ini ada tiga kondisi yang telah dievaluasi, yaitu nilai susut transmisi pada kondisi real, pada saat semua kapasitor diaktifkan dan pada saat semua kapasitor dinonaktifkan. Dari hasil penelitian menunjukkan perbedaan nilai susut transmisi dari ketiga kondisi tersebut. Dimana nilai susut transmisi terkecil yaitu pada kondisi kedua sebesar 1,69\% dan nilai susut transmisi terbesar yaitu pada kondisi ketiga sebesar $1,76 \%$.
}

Kata Kunci - Kapasitor, shunt, simulasi, susut transmisi, DIgSILENT

\section{Pendahuluan}

Peranan energi listrik dalam menjalankan berbagai aktivitas masyarakat sangat penting. Energi listrik telah menjadi kebutuhan primer bagi masyarakat itu sendiri. Oleh karena itu, penyaluran listrik yang berkualitas dan kontinyu sangat diperlukan untuk memenuhi kebutuhan masyarakat. Hal ini membuat PT. PLN (Persero) tak henti - hentinya melakukan kajian, perbaikan dan pengembangan infrastruktur pendukung tersedianya listrik. Salah satu cara yang digunakan adalah dengan membuat sistem interkoneksi yang merupakan sistem terintegrasinya pusat pembangkit, transmisi dan pusat beban.

Dalam penyaluran tenaga listrik dari sumber energi listrik ke pusat beban yang letaknya berjauhan selalu mengalami susut transmisi. Besarnya susut transmisi bergantung pada jenis dan panjang saluran penghantar, tipe jaringan distribusi, kapasitas trafo, tipe beban, faktor daya, dan besarnya jumlah daya terpasang serta banyaknya pemakaian beban - beban induktif yang menyebabkan meningkatnya kebutuhan daya reaktif. Salah satu cara mengurangi susut transmisi adalah dengan memasang kapasitor shunt pada titik - titik tertentu di saluran distribusi. Dimana kekurangan daya reaktif yang dibutuhkan oleh beban sedapat mungkin dipenuhi oleh kapasitor shunt.

Sistem tenaga listrik modern merupakan sistem yang komplek yang terdiri dari pusat 
pembangkit, saluran transmisi dan jaringan distribusi yang berfungsi untuk menyalurkan daya dari pusat pembangkit ke pusat beban. Untuk memenuhi tujuan operasi sistem tenaga listrik, ketika bagian yaitu pembangkit, penyaluran dan distribusi tersebut satu dengan yang lainnya tidak dapat dipisahkan [1].

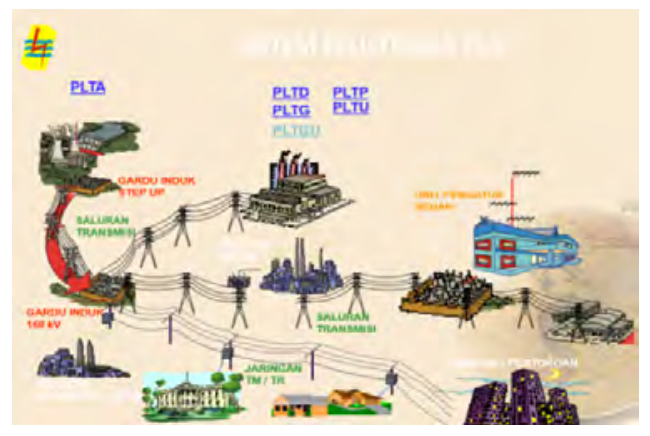

Gambar 1. Sistem Tenaga Listrik

Berdasarkan gambar 1 dapat diamati proses penyaluran energi listrik yang berasal dari pusat pembangkit hingga ke pusat beban. Energi listrik yang dihasilkan pusat pembangkit dinaikkan tegangannya menggunakan transformator step up dengan maksud untuk mengurangi jumlah arus yang mengalir pada saluran transmisi. Ketika saluran transmisi mencapai pusat beban, tegangan tersebut akan diturunkan lagi melalui transformator step - down yang terdapat pada gardu distribusi menjadi tegangan menengah maupun tegangan rendah yang kemudian akan disalurkan melalui distribusi menuju pusat pusat beban.

Semakin berkembangnya sistem berarti semakin tingginya konsumsi tenaga di wilayah tersebut. Salah satu cara yang dilakukan untuk mengatasi tingginya konsumsi tersebut adalah dengan melakukan interkoneksi antara beberapa wilayah, yang bertujuan untuk menyuplai daya ke wilayah yang mengalami kekurangan daya. Pembangkit - pembangkit yang terinterkoneksi pada sistem Sulselbar terdiri dari PLTA Bakaru, PLTA Poso, PLTU Barru, PLTA Bili - bili, PLTM Sawitto, PLTM Bungin, PLTD Suppa, PLTGU Sengkang, PLTU Jeneponto, PLTA Tangka, PLTD Tallasa, PLTD Tello [2].
Penggunaan kapasitor shunt pada sistem interkoneksi berfungsi untuk memeperbaiki faktor daya jaringan, mengurangi rugi - rugi (losses) jaringan, menetralkan/meniadakan jatuh tegangan dan memperbaiki stabilitas tegangan. Dengan kata lain, kapasitor shunt akan menaikkan angka efisiensi pada jaringan dengan memperbaiki faktor daya. Dari gambar 2 dapat dilihat bentuk fisik dari kapasitor shunt [3].

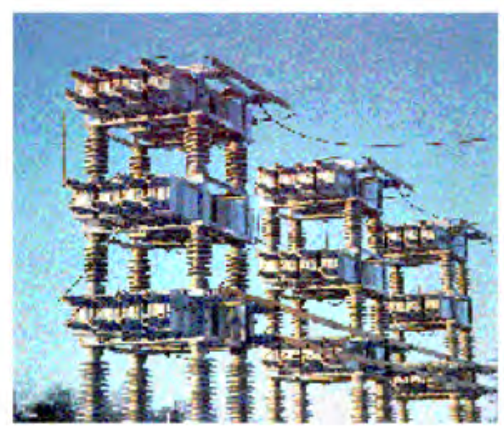

Gambar 2. Kapasitor Shunt

\section{Metode Penelitian}

\section{A. Perhitungan Susut Transmisi}

Gambar 3 menunjukkan suatu sistem sederhana yang menghubungkan dua stasiun pembangkit dengan sebuah beban.

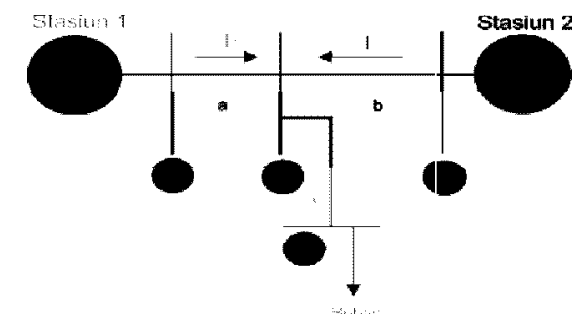

Gambar 3. Sistem Penyaluran listrik sederhana [4]

Jika resistansi a, b dan c dinyatakan secara berturut - turut sebagai $\mathrm{R}_{\mathrm{a}}, \mathrm{R}_{\mathrm{b}}, \mathrm{R}_{\mathrm{c}}$, maka kehilangan daya total untuk sistem transmisi tiga fasa dinyatakan sebagai berikut [5]:

$$
=3|++3|+|+3|+\mid
$$

Jika diasumsikan $I_{1}$ dan $I_{2}$ sefasa,

$$
1+1=1+1
$$


Maka diperoleh penyederhanaan dari daya total yang hilang sebagai berikut :

3||$(+)+3||(+)+3 \times 2|||| \mid$

dimana :

$\mathrm{P}_{\mathrm{L}} \quad$ : daya total yang hilang pada saluran transmisi (MW)

$\mathrm{Ra} \quad$ : hambatan saluran a $(\Omega)$

$\mathrm{Rb} \quad$ : hambatan saluran $\mathrm{b}(\Omega)$

Rc $\quad$ : hambatan saluran c $(\Omega)$

Secara umum, nilai susut transmisi dapat ditentukan dengan menghitung selisih daya dari sisi pengirim dan sisi penerima [6].

$\mathrm{P}_{\mathrm{ST}}=\mathrm{P}_{\mathrm{S}}-\mathrm{P}_{\mathrm{R}}$

dimana :

$\mathrm{P}_{\mathrm{ST}} \quad$ : susut transmisi (MW)

$\mathrm{P}_{\mathrm{S}} \quad$ : daya di sisi pengirim/sender (MW)

$P_{R} \quad$ : daya di sisi penerima/recipient (MW)

\section{B. Efisiensi Transmisi ( $\eta)$}

Untuk mengetahui tingkat efisiensi daya yang disalurkan, maka perlu untuk menentukan nilai efisiensi daya pada setiap saluran transmisi. Secara umum, efisiensi dapat dihitung dengan membandingkan daya yang ada pada sisi penerima dan daya yang ada pada sisi pengirim, seperti pada persamaan 5 [7].

$$
=-\times 100 \%
$$

dimana :

$\eta \quad$ : efisiensi (\%)

$\mathrm{P}_{\mathrm{S}} \quad$ : daya di sisi pengirim/sender (MW)

$P_{R} \quad$ : daya di sisi penerima/recipient (MW)

\section{Hasil dan Pembahasan}

\section{A. Hasil Simulasi Pengaruh Kapasitor Shunt}

Setelah dilakukan simulasi pada saat kapasitor shunt terpasang, diperoleh nilai susut transmisi pada saluran, maka selanjutnya dilakukan pelepasan dari kapasitor shunt dan mengevaluasi perubahan nilai susut yang terjadi. Pada hasil simulasi dengan menggunakan software DigSILENT, diperoleh nilai daya aktif maupun daya reaktif dari bus pengirim dan penerima. Untuk membedakan antara kedua jenis Bus tersebut dapat dilihat dengan tanda negatif (-) dan positif $(+)$. Apabila daya pada salah satu bus bertanda negatif (-) maka dapat diartikan bus tersebut merupakan bus penerima. Begitupun sebaliknya, bila tanda positif mendakan bahwa Bus tersebut merupakan bus pengirim.

Pada penelitian ini, simulasi dilakukan pada 3 kondisi yang berbeda-beda, yaitu pada kondisi real pada tanggal 02 Februari 2016 dimana kapasitor shunt yang diaktifkan hanya ada dua buah. Dilanjutkan dengan simulasi pada saat semua kapasitor shunt diaktifkan serta pada saat semua kapasitor shunt di nonaktifkan.

\section{1) Kondisi-1 : keadaan real}

Pada kondisi ini terdapat dua kapasitor shunt yang aktif, yaitu kapasitor shunt pada busbar Tello $70 \mathrm{kV}$ dan pada busbar Pangkep $70 \mathrm{kV}$. Dengan memilih PLTU Jeneponto sebagai swing bus karena pembangkit tersebut merupakan pembangkit yang memiliki daya yang dibangkitkan paling besar di Sistem Sulselbar.

Setelah menjalankan simulasi pada software DIgSILENT dilakukan pengamatan pada saluran transmisi yang menghubungkan Bus Tello 150 $\mathrm{kV}$ - Bus Tallo Lama $150 \mathrm{kV}$, saluran transmisi yang menghubungkan Bus Borongloe $70 \mathrm{kV}$ Tello $70 \mathrm{kV}$, dan saluran transmisi yang menghubungkan Bus Tello $70 \mathrm{kV}$ - Bus Daya 70 $\mathrm{kV}$.

Berdasarkan persamaan (5) dapat diperoleh nilai efisiensi susut yakni daya di sisi penerima dibandingkan dengan daya di sisi pengirim dalam persen. Sebagai contoh dapat diamati dari 
saluran yang menghubungkan Bus Borongloe Bus Tello $70 \mathrm{kV}$. Pada sisi penerima diperoleh daya sebesar 4,5789 MW dan daya di sisi pengirim yakni sebesar 4,5990 MW, sehingga :

$$
\text { Efisiensi }(\eta)=\frac{,}{,} \times 100 \%=99,56 \%
$$

Dengan cara yang sama, diperoleh nilai efisiensi susut untuk setiap saluran seperti pada tabel 1, 2 dan 3.

Tabel 1. Susut transmisi saat kondisi-1

\begin{tabular}{|c|c|c|c|c|c|c|c|c|c|}
\hline \multirow[b]{2}{*}{ No } & \multirow[b]{2}{*}{ Saluran } & \multirow[b]{2}{*}{$\begin{array}{c}\text { Panjang } \\
\text { Saluran }(\mathrm{km})\end{array}$} & \multicolumn{2}{|c|}{ Bus i } & \multicolumn{2}{|c|}{ Bus j } & \multicolumn{2}{|c|}{ Susut Transmisi } & \multirow[b]{2}{*}{$\begin{array}{c}\text { Efisiensi } \\
\text { Daya } \\
\text { Aktif }(\%)\end{array}$} \\
\hline & & & $\begin{array}{l}\text { Daya } \\
\text { Aktif } \\
(\mathrm{MW}) \\
\end{array}$ & $\begin{array}{c}\text { Daya } \\
\text { Reaktif } \\
\text { (MVAR) }\end{array}$ & $\begin{array}{l}\text { Daya } \\
\text { Aktif } \\
(\mathrm{MW}) \\
\end{array}$ & $\begin{array}{c}\text { Daya } \\
\text { Reaktif } \\
\text { (MVAR) }\end{array}$ & $\begin{array}{l}\text { Daya } \\
\text { Aktif } \\
(\mathrm{MW})\end{array}$ & $\begin{array}{c}\text { Daya } \\
\text { Reaktif } \\
\text { (MVAR) }\end{array}$ & \\
\hline 1 & $\begin{array}{c}\text { Borongloe - } \\
\text { Tello } 70\end{array}$ & 12,4 & $-4,5789$ & 3,0698 & 4,5990 & $-3,1375$ & 0,0201 & $-0,0677$ & 99,56 \\
\hline 2 & $\begin{array}{c}\text { Tello150 - } \\
\text { Tallo } \\
\text { Lama150 }\end{array}$ & 6,9 & 74,6270 & 25,6556 & $-74,5406$ & $-26,1116$ & 0,0864 & $-0,4560$ & 99,88 \\
\hline 3 & $\begin{array}{c}\text { Tello70 - } \\
\text { Daya }\end{array}$ & 7.3 & 19,1686 & 6,5511 & -18.9925 & $-6,4110$ & 0,1761 & 0,1401 & 99,08 \\
\hline
\end{tabular}

Berdasarkan tabel 1, dapat diketahui bahwa diantara tiga saluran yang dijadikan tolak ukur penelitian, saluran Tello $150 \mathrm{kV}-$ Tallo Lama $150 \mathrm{kV}$ merupakan saluran yang nilai efisiensinya paling baik, sedangkan saluran yang memiliki nilai susut transmisi daya aktif paling rendah adalah saluran Borongloe - Tello $70 \mathrm{kV}$.
Adapun nilai susut transmisi untuk keseluruhan sistem Sulselbar yang diperoleh dari hasil simulasi DIgSILENT adalah sebesar 1,72\%.

\section{2) Kondisi-2 : semua kapasitor aktif}

Pada sistem interkoneksi Sulselbar terdapat empat buah kapasitor shunt yang terpasang, yaitu pada Bus Tallo Lama $70 \mathrm{kV}$, Bus Daya $70 \mathrm{kV}$, Bus Tello 70 kV, dan Bus Pangkep 70 kV.

Tabel 2.Susut transmisi saat kondisi semua kapasitor aktif

\begin{tabular}{|c|c|c|c|c|c|c|c|c|c|}
\hline \multirow[b]{2}{*}{ No } & \multirow[b]{2}{*}{ Saluran } & \multirow[b]{2}{*}{$\begin{array}{c}\text { Panjang } \\
\text { Saluran (km) }\end{array}$} & \multicolumn{2}{|c|}{ Bus i } & \multicolumn{2}{|c|}{ Bus j } & \multicolumn{2}{|c|}{ Susut Transmisi } & \multirow{2}{*}{$\begin{array}{c}\text { Efisiensi } \\
\text { Daya } \\
\text { Aktif (\%) }\end{array}$} \\
\hline & & & $\begin{array}{l}\text { Daya } \\
\text { Aktif } \\
\text { (MW) }\end{array}$ & $\begin{array}{c}\text { Daya } \\
\text { Reaktif } \\
\text { (MVAR) }\end{array}$ & $\begin{array}{l}\text { Daya } \\
\text { Aktif } \\
\text { (MW) }\end{array}$ & $\begin{array}{c}\text { Daya } \\
\text { Reaktif } \\
\text { (MVAR) }\end{array}$ & $\begin{array}{l}\text { Daya } \\
\text { Aktif } \\
\text { (MW) }\end{array}$ & $\begin{array}{c}\text { Daya } \\
\text { Reaktif } \\
\text { (MVAR) }\end{array}$ & \\
\hline 1 & $\begin{array}{c}\text { Borongloe - } \\
\text { Tello70 }\end{array}$ & 12,4 & $-4,3559$ & 3,1503 & 4,3743 & $-3,2252$ & 0,0184 & $-0,0749$ & 99,58 \\
\hline 2 & $\begin{array}{c}\text { Tello150 - } \\
\text { Tallo } \\
\text { Lama150 }\end{array}$ & 6,9 & 77,4377 & 17,2353 & $-77,3519$ & $-17,7106$ & 0,0858 & $-0,4753$ & 99,89 \\
\hline 3 & $\begin{array}{c}\text { Tello70 - } \\
\text { Daya }\end{array}$ & 7.3 & 19,9478 & 1,8888 & $-19,7821$ & $-1,7632$ & 0,1657 & 0,1256 & 99,17 \\
\hline
\end{tabular}

Ketika semua kapasitor shunt yang terdapat pada sistem diaktifkan, maka saluran yang memiliki nilai efisiensi susut paling baik adalah saluran Tello $150 \mathrm{kV}$ - Tallo Lama $150 \mathrm{kV}$ dan saluran yang memiliki nilai susut daya aktif paling rendah adalah saluran Borongloe - Tello $70 \mathrm{kV}$.
Sedangkan nilai susut keseluruhan sistem yang diperoleh dari hasil simulasi adalah sebesar 1,69\%.

3) Kondisi-3 : semua kapasitor shunt non - aktif

Tabel 3.Susut transmisi saat kondisi semua kapasitor non - aktif

\begin{tabular}{|c|c|c|c|c|c|c|c|c|c|}
\hline \multirow[b]{2}{*}{ No } & \multirow[b]{2}{*}{ Saluran } & \multirow[b]{2}{*}{$\begin{array}{c}\text { Panjang } \\
\text { Saluran }(\mathrm{km})\end{array}$} & \multicolumn{2}{|c|}{ Bus i } & \multicolumn{2}{|c|}{ Bus $\mathrm{j}$} & \multicolumn{2}{|c|}{ Susut Transmisi } & \multirow{2}{*}{$\begin{array}{c}\text { Efisiensi } \\
\text { Daya } \\
\text { Aktif (\%) }\end{array}$} \\
\hline & & & $\begin{array}{l}\text { Daya } \\
\text { Aktif } \\
\text { (MW) }\end{array}$ & $\begin{array}{c}\text { Daya } \\
\text { Reaktif } \\
\text { (MVAR) }\end{array}$ & $\begin{array}{l}\text { Daya } \\
\text { Aktif } \\
\text { (MW) }\end{array}$ & $\begin{array}{c}\text { Daya } \\
\text { Reaktif } \\
\text { (MVAR) }\end{array}$ & $\begin{array}{l}\text { Daya } \\
\text { Aktif } \\
\text { (MW) }\end{array}$ & $\begin{array}{c}\text { Daya } \\
\text { Reaktif } \\
\text { (MVAR) }\end{array}$ & \\
\hline 1 & $\begin{array}{l}\text { Borongloe - } \\
\text { Tello70 }\end{array}$ & 12,4 & $-4,8683$ & 2,9688 & 4,8910 & $-3,0264$ & 0,0227 & $-0,0576$ & 99,53 \\
\hline 2 & $\begin{array}{c}\text { Tello150 - } \\
\text { Tallo } \\
\text { Lama150 }\end{array}$ & 6,9 & 73,5061 & 25,2702 & $-73,4211$ & $-25,7240$ & 0,0850 & $-0,4538$ & 99,88 \\
\hline 3 & $\begin{array}{l}\text { Tello70 - } \\
\text { Daya }\end{array}$ & 7.3 & 18,0288 & 5,8752 & $-17,8601$ & $-5,7474$ & 0,1687 & 0,1278 & 99,06 \\
\hline
\end{tabular}


Ketika semua kapasitor shunt yang terdapat pada sistem dinonaktifkan, maka saluran yang memiliki nilai efisiensi susut transmisi paling baik adalah saluran Tello $150 \mathrm{kV}$ - Tallo Lama 150 $\mathrm{kV}$ dan saluran yang memiliki nilai susut daya aktif paling rendah adalah saluran Borongloe Tello $70 \mathrm{kV}$.

Adapun nilai susut keseluruhan sistem yang diperoleh dari hasil simulasi adalah sebesar $1,76 \%$.

4) Perbandingan Susut Transmisi antara Kondisi 1, 2 dan 3

Untuk mengetahui perubahan nilai susut transmisi dan efisiensi susut transmisi antara kondisi 1, 2 dan 3, maka dilakukan perbandingan nilai ketiganya pada tabel 4 .
Tabel 5. Perubahan nilai susut transmisi Keseluruhan sistem Sulselbar

\begin{tabular}{|c|c|c|}
\hline No & Kondisi & $\begin{array}{c}\text { Susut Transmisi } \\
(\%)\end{array}$ \\
\hline 1 & Keadaan real & 1,72 \\
\hline 2 & Semua kapasitor aktif & 1,69 \\
\hline 3 & $\begin{array}{c}\text { Semua kapasitor non - } \\
\text { aktif }\end{array}$ & 1,76 \\
\hline
\end{tabular}

kondisi 1, 2 dan 3, maka perbandingan nilai ketiganya dijelaskan pada tabel 5 berikut ini.

Berdasarkan tabel 5 dapat diketahui bahwa persentase susut transmisi keseluruhan sistem terbesar terjadi ketika seluruh kapasitor shunt dinonaktifkan dan persentase susut transmisi keseluruhan sistem paling kecil terjadi ketika seluruh kapasitor shunt diaktifkan

Tabel 4. Perbandingan nilai susut transmisi antara kondisi 1, 2 dan 3

\begin{tabular}{|c|c|c|c|c|c|c|c|c|c|c|}
\hline \multirow{2}{*}{ No } & Saluran & $\begin{array}{c}\text { Susut } \\
\text { Daya } \\
\text { Aktif } \\
\text { (MW) }\end{array}$ & $\begin{array}{c}\text { Susut } \\
\text { Daya } \\
\text { Reaktif } \\
\text { (MVA } \\
\text { R) }\end{array}$ & $\begin{array}{c}\text { Efisiensi } \\
\text { Daya } \\
\text { Aktif } \\
(\%)\end{array}$ & $\begin{array}{c}\text { Susut } \\
\text { Daya } \\
\text { Aktif } \\
\text { (MW) }\end{array}$ & $\begin{array}{c}\text { Susut } \\
\text { Daya } \\
\text { Reaktif } \\
\text { (MVAR) }\end{array}$ & $\begin{array}{c}\text { Efisiensi } \\
\text { Daya } \\
\text { Aktif (\%) }\end{array}$ & $\begin{array}{c}\text { Susut } \\
\text { Daya } \\
\text { Aktif } \\
\text { (MW) }\end{array}$ & $\begin{array}{c}\text { Susut } \\
\text { Daya } \\
\text { Reaktif } \\
\text { (MVAR) }\end{array}$ & $\begin{array}{c}\text { Efisiensi } \\
\text { Daya } \\
\text { Aktif (\%) }\end{array}$ \\
\hline 1 & $\begin{array}{c}\text { Borongloe } \\
- \text { Tello70 }\end{array}$ & 0,0201 & $-0,0677$ & 99,56 & 0,0184 & $-0,0749$ & 99,58 & 0,0227 & $-0,0576$ & 99,53 \\
\hline 2 & $\begin{array}{c}\text { Tello150- } \\
\text { Tallo } \\
\text { Lama150 }\end{array}$ & 0,0864 & $-0,4560$ & 99,88 & 0,0858 & $-0,4753$ & 99,89 & 0,0850 & $-0,4538$ & 99,88 \\
\hline 3 & $\begin{array}{c}\text { Tello70 - } \\
\text { Daya }\end{array}$ & 0,1761 & 0,1401 & 99,08 & 0,1657 & 0,1256 & 99,17 & 0,1687 & 0,1278 & 99,06 \\
\hline
\end{tabular}

Berdasarkan tabel 4 dapat diketahui bahwa untuk saluran Borongloe - Tello $70 \mathrm{kV}$ susut transmisi paling tinggi terjadi pada kondisi ketika semua kapasitor shunt pada sistem dinon aktifkan dan susut transmisi terendah terjadi pada kondisi dimana semua kapasitor shunt diaktifkan. Sedangkan untuk saluran Tello $150 \mathrm{kV}$ - Tallo Lama $150 \mathrm{kV}$ susut transmisi paling tinggi terjadi pada kondisi real dan susut transmisi terendah pada kondisi semua kapasitor shunt dinonaktifkan. Serta untuk saluran Tello $70 \mathrm{kV}-$ Daya susut transmisi tertinggi terjadi pada kondisi real dan susut transmisi terendah terjadi ketika semua kapasitor shuntdiaktifkan.

Adapun untuk nilai efisiensi susut transmisi paling baik untuk ketiga saluran yang dijadikan tolak ukur terjadi ketika semua kapasitor shunt diaktifkan dan nilai efisiensi paling rendah terjadi ketika semua kapasitor shunt dinon aktifkan.

Untuk mengetahui perubahan nilai susut transmisi keseluruhan sistem Sulselbar antara

\section{Kesimpulan}

Berdasarkan hasil penelitian maka kesimpulan yang kami perloeh adalah :

1. Dari ketiga kondisi yang ditinjau, dapat dilihat bahwa persentase susut transmisi terendah terjadi pada saat semua kapasitor shunt diaktifkan sebesar 1,69\%.

2. Untuk persentase susut transmisi tertinggi terjadi pada sat semua kapasitor shunt dinonaktifkan. 
3. Dari hasil simulasi yang didapatkan, kapasitor shunt mempengaruhi perubahan susut transmisi pada sistem interkoneksi Sulselbar. Telihat perbedaan pada beberapa kondisi yang disimulasikan dimana pada saat kapasitor shunt diaktifkan dan pada saat kapasitor shunt dinon - aktifkan terjadi perbedaan susut transmisi.

\section{Daftar Pustaka}

[1] Afandi, A.N.. 2005. Operasi Sistem \& Pengendalian. Malang: Dioma.

[2] Cahyanto, Restu Dwi. 2008. Studi Perbikan Kualitas Tegangan dan Rug - Rugi Daya Penyulang Pupur dan Bedak Menggunakan Bank Kapasitor, Trafo Pengubah Tap dan Penggantian Kabel Penyulang. Laporan Tugas Akhir. Depok. Departemen Teknik Elektro Fakultas Teknik Universitas Indonesia.

[3] DIgSILENT Power Factory 15.1. (User Manual).

[4] Djiteng, Marsudi. 2006. Operasi Sistem Tenaga Listrik. Jakarta: Graha Ilmu.

[5] PLN. 2009. Buku Petunjuk Operasi dan Pemeliharaan Peralatan Penyaluran Tenaga Listrik. Jakarta: PT. PLN (Persero).

[6] Priyadi, Ardyono dkk. 2012. Analisis Stabilitas Transient Pada Sistem Tenaga Listrik dengan Mempertimbangkan Beban Non - Linier. Jurnal. Surabaya. Jurusan Teknik Elektro Fakultas Teknologi Industri Institut Teknologi Sepuluh Nopember (ITS).

[7] RUPTL. 2014. Rencana Usaha Penyediaan Tenaga Listrik (RUPTL) Tahun 2015 - 2024. Jakarta: PT.PLN (Persero).

[8] Stevenson, William D, Jr. 1996. Analisis Sistem Tenaga Listrik. Diterjemahkan oleh Kamal Idris. Bandung. PT. Philips Ralin Electronics.

[9] Wikarsa, Mohamad Tresna. 2010. Studi Analisis Program Percepatan 10.000 MW Tahap 1 pada Operasi Sistem Tenaga Listrik Jawa Bali. Jurnal. Depok. Departemen Teknik Elektro Fakultas Teknik Universitas Indonesia. 